\title{
Pioneers and champions for the little hearts: A history of pediatric cardiology in Nepal
}

\author{
Poonam Sharma
}

Cite this article as: Sharma P. Pioneers and champions for the little hearts: A history of pediatric cardiology in Nepal. Nepalese Heart Journal 2018; 15(2): 1-2.

DOI: http://dx.doi.org/10.3126/njh.v15i2.21468

Heart disease in a child requires complex set of expertise as physiology and challenges presented in pediatric cardiology are much different from adult cardiology. In preclinical era of renaissance, children and adults were examined by the same physician. At the outset of 20th century, the need for a special center for children with heart disease was identified as several authors began to add specific sections devoted to congenital heart disease in books of anatomy and pediatrics. A major milestone was reached when Helen Taussig, in charge of cardiac clinic in Harriet Lane Hospital, Baltimore, USA, established pediatric cardiology center for the first time. ${ }^{1}$ Pediatric cardiology gained further prominence in 1938 when Robert Gross successfully ligated the patent ductus arteriosus in a seven year old girl. ${ }^{2}$ The first successful creation of systemic to pulmonary shunt by Blalock and Taussig in 1944 boldly introduced surgical interventions. The field of pediatric cardiology has been making remarkable developments, with dramatic improvements in diagnostic tools, and with cardiac surgeons constantly pushing the envelope, culminating in being first subspecialty board of pediatrics in USA in $1961 .^{4}$ These developments have changed the outlook of cardiac diseases in children and instilled hope for cure in previously untreatable disorders. Interestingly, advances made in pediatric cardiology have provided expertise in the treatment of adult congenital heart diseases.

Despite the rapid advancements elsewhere, the field of pediatric cardiology was not recognized as a distinct specialization in Nepal until two decades ago. Some fortunate children benefited when the earliest attempts to diagnose and treat children with congenital heart disease started with the introduction of echocardiography service in Bir hospital in 1985.5 The hospital, however, could not cope with the increasing demands of children with heart problems due to its small pediatric unit.

Though Nepal's only pediatric hospital, Kanti Children's Hospital (KCH) was established in 1970, it could not deliver focused treatment on pediatric cardiology due to lack of trained cardiac pediatricians, and due to tremendous needs in providing basic health care in children. ${ }^{6,7}$ In these early years, the only diagnostic tools available were clinical examination, stethoscope, and chest $\mathrm{x}$-ray. Many patients had to be referred to foreign countries for a diagnosis and treatment. ${ }^{8}{ }^{89}$ However, significant progress was made when Dr. Laxman Tibrewal, building on success at Bir Hospital, took to performing 2D echocardiography using the newly donated machine from Japanese government at $\mathrm{KCH}$ in $1984 .^{7}$ However it took another decade before cardiac OPD services to be started in 1995 by Dr. Ranendra Prakash Bahadur Shrestha, the then incharge of pediatric and neonatal intensive care unit of $\mathrm{KCH} .{ }^{10}$

Prof. Dr. Anne Wedemeyer a pediatric cardiologist from USA recognized the palpable gap in pediatric cardiology service in Nepal. In 1998, owing to her tireless efforts and multiple subsequent visits to Nepal to train pediatricians on specialized cardiac care, inpatients services for pediatric cardiac patients was established, and pediatric cardiology subspecialty began in earnest in Nepal. ${ }^{10,11}$ Despite the establishment of pediatric cardiology discipline, an acute shortage of trained specialists to diagnose and manage the complexity of pediatric cardiology was felt. Many pediatricians tended to remain abroad after completing their cardiac specialty education and those who returned, practiced general pediatrics due to lack of basic infrastructure, logistics and venue to practice the advanced skills earned abroad.

At the turn of 21 st century, the creation of Shahid Gangalal National Heart Center (SGNHC), a first of its kind and prominence, gave a huge boost to the field of cardiology in Nepal. The diagnosis and management of patients with heart disease received much-needed ray of sunshine after experiencing decades of gloomy outcomes. Soon, children admitted to Kanti Hospital, looking for better intervention found hope at the National Heart Center receiving echocardiography and corrective surgery. Some of the earliest cardiologist performing echocardiography in children included Dr. Deewarkar Sharma, Dr. Rabi Malla and Dr. Arun Maskey. Cardiac catheterization was initiated by Dr. Rabi Malla and Dr. Shyam Raj Regmi and percutaneous device closures by Dr. Yadav Bhatta in its early days. ${ }^{12}$ Despite the remarkable increase in cardiology services to children, pediatric cardiology unit was opened at the SGNHC only when Dr. Urmila Shakya after her training in pediatric cardiology joined the hospital in 2003.12,13 Since then, under her dedication and guidance, pediatric cardiology unit in the hospital has routinely expanded its capabilities. Complex procedures such as percutaneous valvular dilatation for obstructive valvular lesions were now being performed routinely. Fetal echocardiography, which is an integral part of prenatal diagnosis for congenital cardiac anomalies was initiated by Dr. Deewakar Sharma in SGNHC in 2007. 14 Building on the successes, the pediatric heart center has ventured into previously unimaginable interventions, performing routine therapeutic interventions such as device closures, patent ductus arteriosus (PDA) stenting, major aortopulmonary collateral arteries (MAPCA) coiling and balloon atrial septostomy.

Pediatric cardiology is perhaps one of the few specialties where diagnosis and management of the disease inevitably leads to children requiring major cardiac surgeries. Although cardiac surgery had been performed in Nepal since 1965, it was done with the leadership of international surgeons visiting from Australia and USA. ${ }^{15}$ Nepalese surgeons were participating as collaborator and assistants to the visitors, until Dr. Bagwan Koirala lead an all Nepalese team and performed the first successful ASD closure in 1997. It was then possible to imagine that children with heart

@Nepalese Heart Journal. Nepalese Heart Journal retains copyright and work is simultaneously licensed under Creative Commons Attribution License CC - BY 4.0 that allows others to share the work with an acknowledgement of the work's authorship and initial publication in this journal. 
disease could be managed entirely by the resources readily available in Nepal. ${ }^{16}$

The progress experienced by the field of pediatric cardiology in Nepal, however, is very Kathmandu-centric with much of Nepalese children depend on services provided by centers in Kathmandu. Outside the capital, pediatric cardiology services are largely confined to clinical diagnosis and referral to the center. BP Koirala Institute of Health Sciences (BPKIHS), Dharan; Manipal medical college, Pokhara; Chitwan Medical College, Chitwan; Amda Hospital, Butwal and Kathmandu university Teaching Hospital, Dhulikhel, are some of the centers outside Kathmandu that perform echocardiography in suspected cases before referring patients for the definite diagnosis and management. ${ }^{17-19}$ Currently, open heart surgery is primarily being done in SGNHC and Manmohan Cardiothoracic Vascular and Transplant Centre and sporadically in Norvic Hospital, Greencity Hospital, Nepal Mediciti Hospital, Human Organ Transplant Centre all within Kathmandu along with Kathmandu University Teaching Hospital, Dhulikhel and College of Medical Sciences, Chitwan.

Even when progress is needed to provide the pediatric cardiology services to far-flung places, a laudable initiative has bridged the gap of needs for families lacking financial wherewithal to provide necessary care. When it comes to providing expensive care with uncertain outcome to their child, parents are too often faced with difficult decisions. A noble initiative of "No child shall die of heart disease because of poverty," was firmly declared under the leadership of Dr Bhagwan Koirala under which Children Assisted Program (CAP) was started by the government in 2006/2007, where surgical interventions are provided free of cost to children of less than fifteen years of age. This program has provided a critical relief to the parents and even a bigger relief to the treating physicians, with over seven thousand beneficiaries till date..$^{20}$

Other efforts in preventive aspect of pediatric cardiology were initiated by the establishment of Nepal Heart Foundation by Dr. Mrigendra Raj Pandey in 1988. With collaboration with NHF, in 2007, the government of Nepal have launched "National Rheumatic Fever and Rheumatic Heart Disease Prevention and Control Program" to screen school going children and provide penicillin injection free of cost in regional, zonal and national level hospitals. ${ }^{21}$

\section{Conclusion:}

The future of pediatric cardiology services in Nepal looks very promising - owing to the pioneering work done by the early cardiologists. A crop of new generation of pediatric cardiologists is working with new zeal to simultaneously advance the capabilities, while spreading the services to various strata within Nepal. Advances in the areas of diagnosis, including cardiac MRI and 3D printing are on the horizon. Percutaneous valve implantation and other fetal cardiac interventions are well within reach to promote the area of therapeutic interventions. The new generation of pediatric cardiologists is standing on the shoulders of the early giants as they work towards bridging the gap of services between Nepal and the rest of the world.

\section{References}

1. Noonan JA. A History of Pediatric Specialties: The Development of Pediatric Cardiology. Pediatr Res. 2004 Aug; 56(2):298-306.

https://doi.org/10.1203/01.PDR.0000132662.73362.96
2. Mormile R, Quadrini I, Squarcia U. Milestones in Pediatric Cardiology: Making Possible the Impossible. Clin Cardiol. 2013 Feb 1;36(2):74-6. https://doi.org/10.1002/clc.22087

3. Braile DM, Godoy MF de. History of heart surgery in the world. Rev Bras Cir Cardiovasc . 2012;27(1):125-34. https://doi.org/10.5935/1678-9741.20120019

4. Agarwala B. History of development of pediatric cardiology. J Clin Exp Cardiolog . 2016;07(06(Suppl)).

5. Karki DB. Development of cardiology in Nepal. Souvenir Bir Hosp Centenary;1989-90 :105-6.

6. Kanti Children's Hospital, Annual Report. Various Years.

7. A journey from $\mathrm{KH}$ to $\mathrm{KCH} \mid \mathrm{Kanti}$ Childrens Hospital. www.kantichildrenhospital.gov.np

8. Basnet NB, Hishi T, Yanagisawa M. Heart Disease in Nepali Children. Pediatr Cardiol . 2001 Mar 1;22(2):170. https://doi.org/10.1007/s002460010190

9. Saxena A. History of pediatric cardiology in India. J Pract Cardiovasc Sci . 2015;1(2):203. https://doi.org/10.4103/2395-5414.166318

10. Shrestha RPB. Letter sent to government of Nepal from Kanti children hospital for approval of grant for echocardiography equipment. 2001.

11. Basnet NB, Andrews J, Shrestha RM. Pediatric Cardiology and Children's Heart Care in Nepal. J Nepal Med Assoc . 2004 Sep 1. https://doi.org/10.31729/jnma.499

12. Shahid Gangalal National Heart Center, Annual Report. Various Years.

13. Sharma D, KC MB, Rajbhandari S, Maskey A, Malla R, Limbu YR, Rajbhandari R, Bhatta YD, Regmi SR, Shakya U, Kansakar SBS. Echocardiographic profile of congenital heart diasease at ShahidGangalal National Heart Centre. NEPAS J. 2005;25:11-4.

14. Regmi S, Sharma D. Fetal Echocardiography: Short Term Profile from Shahid Gangalal National Heart Centre, Kathmandu, Nepal. Nepal Hear J . 2016 Feb 12;13(1):9. http://dx.doi.org/10.3126/njh.v13i1.14538

15. Hosain N, Amin F, Rehman S, Koirala B. Know thy neighbors: The status of cardiac surgery in the South Asian countries around India. Indian Heart J . 2017 Nov $1 ; 69(6): 790-6$. https://doi.org/10.1016/j.ihj.2017.09.219

16. Koirala B. Beginning of open heart surgery in Nepal. J Nepal Med Assoc. 1998;37:447-8. https://doi.org/10.31729/jnma.1179

17. Humagain S, Twayana R, Koju R. Echocardiographic Profile of Patients in Dhulikhel Hospital, A Medical College Hospital in Nepal. Nepal Hear J . 2014 Sep 1;11(1):13-7. https://doi.org/10.3126/njh.v11i1.10976

18. Joshi A, Shrestha RP, Shrestha PS, Dangol S, Shrestha NC, Poudyal P, et al. Pattern of Cardiac Diseases in Children Attended at Dhulikhel Hospital, Nepal. Kathmandu Univ Med J (KUMJ); 2016;14(55):239-43.

19. Ramachandran U, Alurkar V, Thaplia A. Pattern of cardiac diseases in children in Pokhara, Nepal. Kathmandu Univ Med J (KUMJ); 2006; 4(2):222-7.

20. Treatment expenditure related annual report of Community Assisted Program patients (SGNHC). 2017.

21. Regmi PR, Wyber R. Prevention of Rheumatic Fever and Heart Disease: Nepalese Experience. Glob Heart . 2013 Sep 1; 8(3):247-52. https://doi.org/10.1016/j.gheart.2013.08.001 